\title{
Bacillus Calmette-Guerin Increases Base Excision Repair in Bladder Cancer Cells
}

\author{
(D) Selçuk Keskin1, (1) Berna Somuncu22, (1) Meltem Müftüoğlu2 \\ ${ }^{1}$ Acibadem Mehmet Ali Aydinlar University, School of Medicine, Department of Urology, İstanbul, Turkiye \\ ${ }^{2}$ Acibadem Mehmet Ali Aydinlar University, Graduate School of Health Sciences, Department of Medical Biotechnology, Istanbul, Turkiye
}

\section{What's known on the subject? and What does the study add?}

Bacillus Calmette-Guerin (BCG) has been shown to increase reactive oxygen species and thus oxidative DNA damage in bladder cancer (BC) cells repaired by base excision repair (BER) pathway. Therefore, the BER capacity of BC cells could be an important factor in response to BCG therapy. We have demonstrated that BCG treatment increased the activities of uracil-initiated total BER and BER enzymes, uracil DNA glycosylase, 8-oxoguanine DNA glycosylase and DNA polymerase $\beta$, in the repair periods in BC transitional carcinoma cell line.

\begin{abstract}
Objective: Most patients with non-muscle-invasive bladder cancer (NMIBC) do not respond to intravesical Bacillus Calmette-Guerin (BCG) immunotherapy and have high risk of NMIBC recurrence and progression. In addition to its therapeutic effect which increases the local immune response, BCG also exerts an anti-tumour effect by increasing oxidative stress, and producing reactive oxygen species and oxidative DNA damage in bladder cancer (BC) cells. The oxidative DNA damage is repaired by base excision repair (BER) mechanism. Thus, BER capacity of BC cells could be an important factor in response to BCG therapy. Effects of BCG on the activity of BER in BC transitional carcinoma cell line, T24 have been investigated. Materials and Methods: The uracil-initiated total BER and BER enzyme activities were measured in whole cell extracts with or without BCG treatment using a $[\gamma-32 \mathrm{P}]$ adenosine triphosphate-labelled 51-mer DNA substrates.

Results: BCG treatment increased the activities of uracil-initiated total BER and BER enzymes, uracil DNA glycosylase and DNA polymerase $\beta$ in $6 \mathrm{~h}$ and $24 \mathrm{~h}$ repair periods and increased the activity of 8-oxoguanine DNA glycosylase in $6 \mathrm{~h}$ repair in T24 BC cell line.

Conclusion: The enhanced BER activity in BC cells in response to BCG treatment could be an important factor in BCG resistance.

Keywords: Base excision repair, bladder cancer, Bacillus Calmette-Guerin
\end{abstract}

\section{Introduction}

Bladder cancer (BC) is the seventh most prevalent cancer in Turkiye and the ninth most common malignancy worldwide (1) (www.who.int). The majority of BC cases are non-muscleinvasive $\mathrm{BC}$ (NMIBC) and includes pathological stages Ta, T1 and carcinoma in situ (2). Approximately $30-80 \%$ of NMIBC will recur and approximately 10-20\% will progress to muscleinvasive disease. Intravesical Bacillus Calmette-Guerin (BCG) immunotherapy is the most efficient adjuvant therapy for intermediate and high risk NMIBC after transurethral resection of bladder tumour (3-5).
Approximately 50\% of patients with NMIBC do not respond to intravesical BCG immunotherapy, making them at high risk of NMIBC recurrence and progression. The mechanism of action has not been fully understood; however, intravesical administration of BCG in NMIBC shows its effect through increasing the local immune response (6-8). It has also been demonstrated that BCG enhances oxidative stress in BC cells, which contributes to the anti-tumour efficacy of BCG $(9,10)$. BCG increases the production of reactive oxygen species (ROS) such as hydrogen peroxide and superoxide radicals in BC cells $(9,10)$, causing DNA damage repaired by base excision repair (BER) mechanism (9). BER protect the cells from cell death induced by DNA damaging

Correspondence: Meltem Müftüoğlu PhD, Acıbadem Mehmet Ali Aydınlar University Graduate School of Health Sciences, Department of Medical Biotechnology, İstanbul, Turkiye

Phone: +90 $2165004131 \quad$ E-mail: Meltem.muftuoglu@acibadem.edu.tr ORCID-ID: orcid.org/0000-0001-5372-4780

Received: 13.11 .2020

Accepted: 25.12 .2020

Cite this article as: Keskin S, Somuncu B, Müftüoğlu M. Bacillus Calmette-Guerin Increases Base Excision Repair in Bladder Cancer Cells. J Urol Surg $2021 ; 8(1): 8-12$

๑Copyright 2020 by the Association of Urological Surgery / Journal of Urological Surgery published by Galenos Publishing House. 
agents, thus reducing the therapy efficacy. Therefore, the increased BER capacity is disadvantageous for cancer treatment. In addition, reduced BER activity and increased oxidatively induced DNA damage lead to genome instability and trigger the development of sporadic cancers (11), thus the BER capacity of $B C$ cells could be an important factor in BCG therapy response.

The BER pathway is started with base excision by a DNA glycosylase enzyme, followed by the apurinic/apyrimidinic (AP) site cleavage by AP endonuclease 1 (APE1). Then, DNA polymerase $\beta$ (Pol $\beta$ ) synthesises a single nucleotide to fill the gap, and DNA ligase seals the nick. DNA glycosylases are lesion-specific enzymes, for example, uracil DNA glycosylase (UDG), which is a major DNA glycosylase for uracil lesion and 8-oxoguanine DNA glycosylase (OGG1), which excises 8-hydroxy-7 and 8-dihydroguanine (8-oxoG) mainly (12). Several studies showed that changes in BER gene expression in BC tissues can affect the initiation and progression of $B C(13-16)$. We have recently demonstrated that NMIBC tissues have increased BER activity compared to corresponding normal tissue from the same person, suggesting that enhanced BER activity may play a role in the aetiology and prognosis of NMIBC progression or response to genotoxic therapeutics (17). BCG increases oxidative stress and ROS production in BC cells $(9,10)$ and causes DNA damage repaired by BER mechanism (9), thus effects of BCG on BER activity in T24 BC (transitional cell carcinoma) cell line has been investigated.

\section{Materials and Methods}

\section{BCG Treatment to T24 BC Cell Line}

T24 BC cell line was purchased from the American Type Culture Collection (ATCC HTB4; no ethical requirements for purchased cell lines). T24 cells are human urinary bladder transitional carcinoma epithelial cell line. T24 cell line were grown in Roswell Park Memorial Institute (RPMI) 1640 medium (GibcoLife Technologies, USA) with 10\% fetal bovine serum (FBS) (Gibco-Life Technologies, USA) and 1\% Pen/Strep (Gibco-Life Technologies, USA). T24 cells were counted and plated in the RPMI growth medium at $3 \times 10^{5}$ cells per plate and incubated overnight at $37{ }^{\circ} \mathrm{C}$ with $5 \% \mathrm{CO}_{2}$ incubator. The next day, T24 cells were treated with $3 \times 10^{6} \mathrm{CFU} / \mathrm{mL}$ BCG (OncoTICE contains live mycobacteria, USA) in RPMI medium containing 10\% FBS and incubated $2 \mathrm{~h}$ at $37{ }^{\circ} \mathrm{C}$ with $5 \% \mathrm{CO}_{2}$ incubator $(9,10)$. At the end of the incubation, BCG was removed and cultures were washed twice with $1 \mathrm{X}$ phosphate-buffered saline, and the new medium without BCG was replaced. Cells were incubated for 6 $\mathrm{h}$ and $24 \mathrm{~h}$ at $37^{\circ} \mathrm{C}$ for repair. After the recovery (repair) period cells were washed once with 1XPBS and were harvested for the whole cell lysates preparation.

\section{Whole Cell Extracts Preparation}

Whole cell extracts were prepared as previously described (17). Briefly, T24 cells were collected by centrifugation at $500 \mathrm{xg}$. Cell extracts were prepared using a Dounce glass-glass homogeniser in appropriate buffers. Protein concentration was determined with the Bio-Rad protein assay (Bio-Rad, USA).

\section{Oligodeoxynucleotides}

Oligodeoxynucleotide sequences are as follows: $U$ = Uracil: $5 '-$ GCTTAGCTTGGAATCGTATCATGTAUACTCGTGTGCCGTGTAGACCG TGCC-3';OHG=8-oxoG:5'-GCTTAGCTTGGAATCGTATCATGTA OHGACTCGTGTGCCGTGTAGACCGTGCC3';X=tetrahidrofuran: 5'-GCTTAGCTTGGAATCGTATCATGTAXACTCGTGTGCCGTGTAG ACCGTGCC-3';1nt-gap:5'-GCTTAGCTTGGAATCGTATCATGTA ACTCGTGTGCCGTGTAGACCGTGCC-3' and

complementarystrand:3'-CGAATCGAACCT TAGCATAGTACATGTGAGCACACGGCACATCTGGCACGG-5'.

All oligodeoxynucleotides were purchased from DNA Technology, Denmark. Oligodeoxynucleotides were 5 '-end-labelled using T4 polynucleotide kinase and $\left[\gamma^{32} \mathrm{P}\right]$ adenosine triphosphate (Perkin Elmer, USA) as described before (17), and were annealed to the complementary strand by incubating at $90{ }^{\circ} \mathrm{C}$ for $5 \mathrm{~min}$ and slowly cooling to room temperature. Radiolabeled substrates were used in DNA glycosylase and APE1 activity assays.

\section{Uracil-initiated Total BER Activity}

The total BER reactions were performed as previously described (17). Briefly, reactions containing $2 \mu \mathrm{Ci}{ }^{32} \mathrm{P}-\mathrm{dCTP}$ (Perkin Elmer, USA), $100 \mathrm{fmol}$ of uracil-containing double-stranded DNA substrate and BER buffer were initiated by $0.5 \mu \mathrm{g}$ whole cell extracts and incubated at $37{ }^{\circ} \mathrm{C}$ for $1 \mathrm{~h}$. Reactions were stopped by adding equal volume of formamide stop dye (90\% formamide, $10 \mathrm{mM}$ EDTA, 0.01\% bromphenol blue and 0.01\% xylene cyanol) and incubated at $37{ }^{\circ} \mathrm{C}$ for $10 \mathrm{~min}$. Samples were then run on 20\% denaturing polyacrylamide gel (PAGE-Urea) and visualised using a Typhoon FLA 9500 Phosphorlmager. Results are presented as the mean \pm standard deviation of three independent experiments.

\section{Activities of DNA Glycosylases}

Incision assays were performed as previously described (17). Briefly, uracil incision reactions containing uracil incision buffer and $100 \mathrm{fmol}$ of ${ }^{32} \mathrm{P}$-labelled uracil-containing DNA substrate were initiated by adding $0.25 \mu \mathrm{g}$ whole cell extract and incubated at $37{ }^{\circ} \mathrm{C}$ for $30 \mathrm{~min}$. The $8-0 x o \mathrm{G}$ incision reactions including 8-0xoG incision buffer and $50 \mathrm{fmol}{ }^{32} \mathrm{P}$-labelled 8-oxoG-containing DNA substrate were initiated by adding $1 \mu \mathrm{g}$ whole cell extracts and incubated at $37{ }^{\circ} \mathrm{C}$ for $30 \mathrm{~min}$. Reactions were stopped by adding equal volume of formamide stop dye containing $100 \mathrm{mM} \mathrm{NaOH}$ and incubated at $75^{\circ} \mathrm{C}$ for $15 \mathrm{~min}$. 
Samples were then run on 20\% PAGE-Urea and visualised using a Typhoon FLA 9500 Phosphorlmager. The percentage of incision was calculated as the amount of radioactivity present in the product band relative to the total radioactivity. Results were presented as the mean \pm standard deviation of three independent experiments.

\section{Gap-filling Assay}

Single-nucleotide gap-filling reactions were performed as previously described (17). Reactions containing $100 \mathrm{fmol}$ of $1 \mathrm{nt}$ gap duplex substrate and $2 \mu \mathrm{Ci}$ of 32P-dCTP (GE Healthcare, USA) were initiated by adding $0.5 \mu \mathrm{g}$ whole cell extract and incubated at $37^{\circ} \mathrm{C}$ for $1 \mathrm{~h}$. Reactions were stopped by adding equal volume of formamide stop dye and incubated at $75{ }^{\circ} \mathrm{C}$ for 15 min. Samples were then run on 20\% PAGE-Urea and visualised using a Typhoon FLA 9500 Phosphorlmager. Results were presented as the mean \pm standard deviation of three independent experiments. The incorporation of ${ }^{32} \mathrm{P}-\mathrm{dCTP}$ was quantified as the increase in the signal intensity. Results were presented as the mean \pm standard deviation of three independent experiments.

\section{Results}

A representative gel for activities of uracil-initiated total $B E R$, uracil incision (UDG activity), 8-OxoG incision (OGG1 activity) and 1nt gap filling (Pol $\beta$ activity) using T24 BC cell extracts with or without treatment of BCG is shown in Figures 1-4, respectively, and in Table 1 . In uracil-initiated total BER assay, the efficiency of ${ }^{32} \mathrm{P}-\mathrm{dCMP}$ incorporation in place of uracil within a 51-mer duplex substrate (Figure 1A-B, 26-mer band) and subsequent ligation (Figure $1 \mathrm{~A}-\mathrm{B}, 51-\mathrm{mer}$ band) were determined. Quantitation of the total BER activity showed that incorporation in addition to ligation activities (Figure 1C) were increased at $6 \mathrm{~h}$ and $24 \mathrm{~h}$ repair periods compared to that of untreated cells (Figure 1C). UDG activity, which is the main enzyme for uracil incision, was increased at $6 \mathrm{~h}$ and $24 \mathrm{~h}$ repair periods compared to untreated cells (Figure 2A-B). OGG1 is the major DNA glycosylase for 8-oxoG incision. OGG1 activity was increased by 1.14 -fold at $6 \mathrm{~h}$ repair period, whereas decreased by 1.53 -fold at $24 \mathrm{~h}$ repair period (Figure 3A-B). Onenucleotide gap-filling activity of Pol $\beta$ in T24 cells was measured. Pol $\beta$ activities were increased at $6 \mathrm{~h}$ and $24 \mathrm{~h}$ repair periods compared to untreated cells (Figure 4A-B).
A

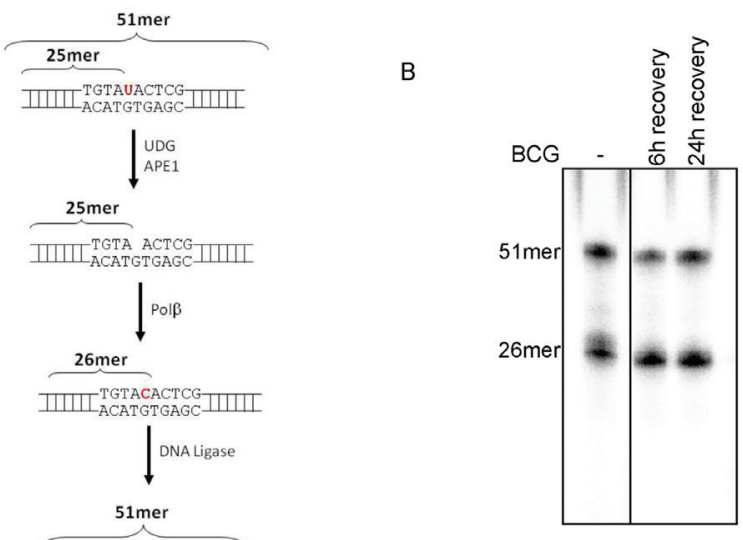

C

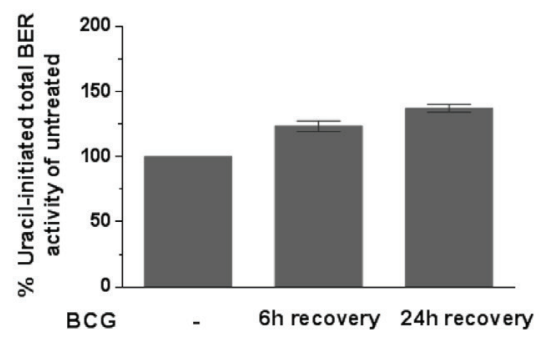

Figure 1. Effects of BCG treatment on the activities of uracil-initiated total BER in T24 BC cell line. A. Schematic of the uracil-initiated total BER assay. A 51 mer DNA substrate containing a uracil at position 26; UDG removes the uracil base and APE1 incises the DNA strand 5 ' to the resulting AP site; Pol $\beta$ synthesizes cytosine base and DNA ligase seals the DNA strand. B. A representative gel for uracil-initiated total BER activity showing products of 32P-dCTP incorporation (26mer) and ligation (51mer). The lower band represents 1-nt incorporation product (26mer) and the upper band represents the 51 mer ligated product. C. Quantitation of the incorporaton plus ligation activities, percent of untreated. The data represent the average \pm standard deviation of three independent experiments

BER: Base excision repair, BC: Bladder cancer, UDG: Uracil DNA glycosylase, BCG: Bacillus Calmette-Guerin, AP: Apurinic/apyrimidinic, APE1: AP endonuclease 1

\section{Discussion}

Several studies demonstrated that BCG causes bladder tumour cytotoxicity because of an immune response to BCG (7). However, BCG has also shown to increase oxidative stress including the generation of nitric oxide, lipid peroxidation, hydrogen peroxide and superoxide radicals in BC cells $(9,10)$. Shah et al. (10) reported that oxidative stress generation in response to

\begin{tabular}{|l|l|l|l|l|}
\hline Table 1. Percent BER activity of untreated cells \\
\hline $\begin{array}{l}\text { Recovery time after } \\
\text { BCG treatment }\end{array}$ & $\begin{array}{l}\text { Percent uracil-initiated total BER } \\
\text { activity of untreated cells }\end{array}$ & $\begin{array}{l}\text { Percent uracil incision } \\
\text { of untreated cells }\end{array}$ & $\begin{array}{l}\text { Percent 8-oxoG incision of } \\
\text { untreated cells }\end{array}$ & $\begin{array}{l}\text { Percent 1-nt incorporation } \\
\text { of untreated cells }\end{array}$ \\
\hline $6 \mathrm{~h}$ recovery & $123.36 \pm 4.15$ & $121.49 \pm 0.76$ & $114.26 \pm 0.09$ & $146.63 \pm 6.13$ \\
\hline $24 \mathrm{~h}$ recovery & $137.06 \pm 2.93$ & $131.28 \pm 0.89$ & $65.54 \pm 0.21$ & $122.99 \pm 3.32$ \\
\hline BER: Base excision repair, BCG: Bacillus Calmette-Guerin \\
\hline
\end{tabular}


A

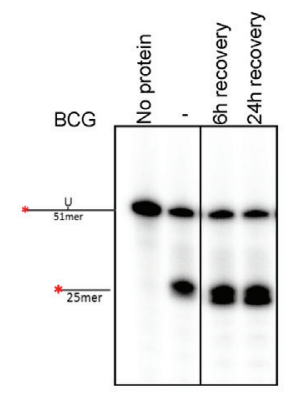

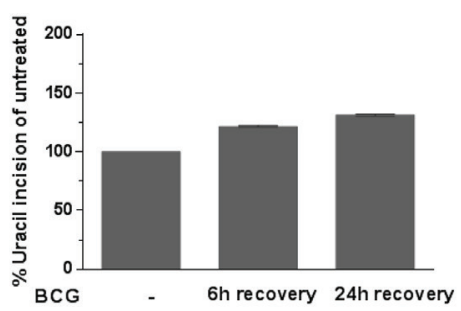

Figure 2. Effects of BCG treatment on the uracil incision in T24 BC cell line. A. Representative gel for uracil incision. Incision products are $25 \mathrm{mer}$ derived from cleaved 32P-labeled 51 mer DNA substrate containing uracil at position 26. B. Quantitation of the uracil incision, percent of untreated. The data represent the average \pm standard deviation of three independent experiments

BCG: Bacillus Calmette-Guerin, BC: Bladder cancer

A

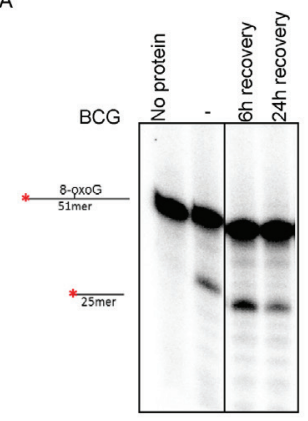

B

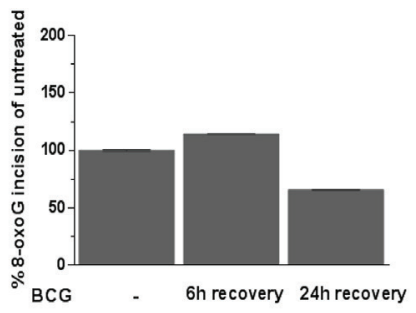

Figure 3. Effects of BCG treatment on the 8-oxoG incision in T24 BC cell line. A. Representative gel for 8-0xoG incision. Incision products are $25 \mathrm{mer}$ derived from cleaved 32P-labeled 51mer DNA substrate containing uracil 8-oxoG at position 26. B. Quantitation of the 8-oxoG incision, percent of untreated. The data represent the average \pm standard deviation of three independent experiments

BCG: Bacillus Calmette-Guerin, BC: Bladder cancer

A

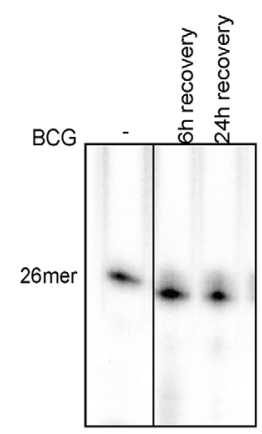

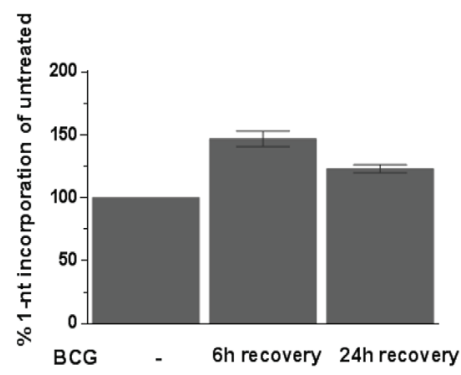

Figure 4. Effects of BCG treatment on single nucleotide gap-filling activity in T24 BC cell line. A. Representative gel for single nucleotide gap-filling activity showing products of $32 \mathrm{P}-\mathrm{dCTP}$ incorporation. B. Quantitation of the single nucleotide gap-filling activity, percent of untreated. The data represent the average \pm standard deviation of three independent experiments

BCG: Bacillus Calmette-Guerin, BC: Bladder cancer

BCG treatment in BC cells may contribute to BCG cytotoxicity. Patients with NMIBC who do not respond to intravesical BCG therapy are at high risk of NMIBC progression and recurrence (6-8). BCG causes oxidative DNA damage (9) repaired by BER mechanism and enhanced BER activity of cancer cells reduces the efficacy of the therapy (11); therefore, we have investigated whether BER activity in BC cells following BCG treatment is an important factor in BCG therapy resistance.

Our results demonstrated that activities of uracil-initiated total BER, UDG and Pol $\beta$ in BC cells were increased in $6 \mathrm{~h}$ and $24 \mathrm{~h}$ repair periods. Consistent with this, Rahmat et al. (9) showed that the level of DNA damage is low in BC cells during BCG recovery. $B C G$ increases the production of hydrogen peroxide and superoxide radicals in $B C$ cells $(9,10)$ that may induce the formation of 8-oxoG DNA lesions and cause an increase in the OGG1 activity at $6 \mathrm{~h}$ recovery. $0 \mathrm{GG} 1$ activity has decreased at $24 \mathrm{~h}$ repair because of the possibility that 8-oxoG DNA lesions induced by BCG were repaired before the $24 \mathrm{~h}$ recovery period. These results indicate that increased total BER and BER enzymes activities in response to BCG treatment may contribute to BCG resistance.

\section{Study Limitations}

Limitation of the present study includes the cell-line based experiment. However, in order to determine the mechanisms of tumorigenesis, drug resistance/development and new biomarkers, the cell line-based experiments are useful. These experiments are necessary before retrospective and prospective studies.

\section{Conclusion}

The enhanced BER activity in BC cells following BCG treatment could be an important factor in BCG therapy resistance. In order to evaluate whether BER enzyme activities could be used as a biomarker for response to $B C G$, retrospective and prospective studies are still needed.

\section{Ethics}

Ethics Committee Approval: T24 BC cell line was purchased from the American Type Culture Collection (ATCC HTB4; no ethical requirements for purchased cell lines).

Informed Consent: T24 cells are human urinary bladder transitional carcinoma epithelial cell line.

Peer-review: Externally peer-reviewed.

\section{Authorship Contributions}

Concept: M.M., S.K., B.S., Design: M.M., S.K., B.S., Data Collection or Processing: M.M., S.K., B.S., Analysis or Interpretation: M.M., 
S.K., B.S., Literature Search: M.M., S.K., B.S., Writing: M.M., S.K., B.S.

Conflict of Interest: No conflict of interest was declared by the authors.

Financial Disclosure: The authors declared that this study received no financial support.

\section{References}

1. Antoni S, Ferlay J, Soerjomataram I, Znaor A, Jemal A, Bray F. Bladder Cancer Incidence and Mortality: A Global Overview and Recent Trends. Eur Urol 2017;71:96-108.

2. Compérat $E$, Larré $S$, Roupret $M$, Neuzillet $Y$, Pignot $G$, Quintens $H$, Houéde $N$, Roy C, Durand X, Varinot J, Vordos D, Rouanne M, Bakhri MA, Bertrand P, Jeglinschi SC, Cussenot O, Soulié M, Pfister C. Clinicopathological characteristics of urothelial bladder cancer in patients less than 40 years old. Virchows Arch 2015;466:589-594.

3. Malmström PU, Sylvester RJ, Crawford DE, Friedrich $M$, Krege $S$, Rintala $E$, Solsona E, Di Stasi SM, Witjes JA. An individual patient data meta-analysis of the long-term outcome of randomised studies comparing intravesical mitomycin C versus bacillus Calmette-Guerin for non-muscle-invasive bladder cancer. Eur Urol 2009;56:247-256.

4. Sylvester RJ, Brausi MA, Kirkels WJ, HoeltI W, Calais Da Silva F, Powell PH, Prescott S, Kirkali Z, van de Beek C, Gorlia T, de Reijke TM; EORTC GenitoUrinary Tract Cancer Group. Long-term efficacy results of EORTC genitourinary group randomized phase 3 study 30911 comparing intravesical instillations of epirubicin, bacillus Calmette-Guerin, and bacillus CalmetteGuerin plus isoniazid in patients with intermediate- and high-risk stage Ta T1 urothelial carcinoma of the bladder. Eur Urol 2010;57:766-773.

5. Shang PF, Kwong J, Wang ZP, Tian J, Jiang L, Yang K, Yue ZJ, Tian JQ. Intravesical Bacillus Calmette-Guerin versus epirubicin for Ta and $\mathrm{T} 1$ bladder cancer. Cochrane Database Syst Rev 2011;CD006885.

6. Packiam VT, Johnson SC, Steinberg GD. Non-muscle-invasive bladder cancer: Intravesical treatments beyond Bacille Calmette-Guerin. Cancer 2017; 123:390-400
7. Rayn KN, Hale GR, Grave GP, Agarwal PK. New therapies in nonmuscle invasive bladder cancer treatment. Indian J Urol 2018;34:11-19.

8. Zuiverloon TC, Nieuweboer AJ, Vekony $\mathrm{H}$, Kirkels WJ, Bangma $\mathrm{CH}_{\text {, }}$ Zwarthoff EC. Markers predicting response to bacillus Calmette-Guerin immunotherapy in high-risk bladder cancer patients: a systematic review. Eur Urol 2012;61:128-145.

9. Rahmat JN, Esuvaranathan K, Mahendran R. Bacillus Calmette-Guerin induces cellular reactive oxygen species and lipid peroxidation in cancer cells. Urology 2012;79:1411.e1415-1420.

10. Shah G, Zielonka J, Chen F, Zhang G, Cao Y, Kalyanaraman B, See W. H2O2 generation by bacillus Calmette-Guerin induces the cellular oxidative stress response required for bacillus Calmette-Guerin direct effects on urothelial carcinoma biology. J Urol 2014;192:1238-1248.

11. Sarasin A, Kauffmann A. Overexpression of DNA repair genes is associated with metastasis: a new hypothesis. Mutat Res 2008;659:49-55.

12. Illuzzi JL, Wilson DM 3rd. Base excision repair: contribution to tumorigenesis and target in anticancer treatment paradigms. Curr Med Chem 2012;19:3922-3936.

13. Chantre-Justino M, Alves G, Britto C, Cardoso A, Scherrer L, Moreira AS, Quirino $R$, Ornellas $A$, Leitao $A$, Lage $C$. Impact of reduced levels of APE1 transcripts on the survival of patients with urothelial carcinoma of the bladder. Oncol Rep 2015;34:1667-1674.

14. Shin JH, Choi S, Lee YR, Park MS, Na YG, Irani K, Lee SD, Park JB, Kim JM, Lim JS, Jeon BH. APE1/Ref-1 as a Serological Biomarker for the Detection of Bladder Cancer. Cancer Res Treat 2015;47:823-833.

15. Choi S, Shin JH, Lee YR, Joo HK, Song KH, Na YG, Chang SJ, Lim JS, Jeon BH. Urinary APE1/Ref-1: A Potential Bladder Cancer Biomarker. Dis Markers 2016;2016:7276502.

16. Sak SC, Harnden $P$, Johnston $C F$, Paul AB, Kiltie AE. APE1 and XRCC1 protein expression levels predict cancer-specific survival following radical radiotherapy in bladder cancer. Clin Cancer Res 2005;11:6205-6211.

17. Somuncu B, Keskin $S$, Antmen FM, Saglican $Y$, Ekmekcioglu A, Ertuzun $T$, Tuna MB, Obek C, Wilson DM 3rd, Ince U, Kural AR, Muftuoglu M. Nonmuscle invasive bladder cancer tissues have increased base excision repair capacity. Sci Rep 2020;10:16371. 